\title{
Investigaciones arqueológicas en Tulor 1
}

Agustín Llagostera, ${ }^{1}$ Ana María Barón ${ }^{1}$ Y Leandro Bravo ${ }^{1}$

\section{Antecedentes}

Tulor es un sector arqueológico de San Pedro de Atacama, que ha sido asimilado con la eponimia del ayllu inmediato. Este sector, de alrededor de un kilómetro de extensión, contiene por lo menos 10 sitios que presentan vestigios arquitectónicos; hay otros sitios sin este tipo de vestigios, pero con cerámica fragmentada en superficie. Entre los primeros destaca, por sus dimensiones y características, aquel nominado como Tulor Pueblo o Tulor 1. Le Paige mencionó por primera vez Tulor 1, diciendo que es "un pueblo muy antiguo totalmente tapado por la arena donde están sumergidas piedras para moler y otras herramientas de trabajo" (Le Paige 1957-58: 66). También en esa oportunidad publicó, por primera vez, un rústico y parcial plano del poblado. Posteriormente, el mismo autor vuelve a describir el mencionado sitio refiriéndose a él como un "pueblo consistente en cuatro grupos de casas que presenta cimientos de tapias", con sepulturas de cuerpos en cuclillas enterrados dentro de las habitaciones y ajuar de alfarería negro pulida (Le Paige 1964: 72). Más tarde publica referencias parciales del sector y un plano de los grupos de ruinas que conforman Tulor como sector arqueológico (Le Paige 1973-74). Por último, Serracino (1976) y Le Paige (1976) dieron a conocer excavaciones que realizaron en el sitio Tulor 4. Estas excavaciones consistieron en pozos de sondeo; estos entregaron información sobre cerámica, clasificada por los investigadores dentro de los períodos II y III de San Pedro de Atacama.

Dentro de la compleja problemática de San Pedro de Atacama, es evidente que una de las etapas menos conocida es la que corresponde a los inicios del Período Agropecuario y de los asentamientos permanentes. Los materiales y colecciones del

1 Instituto de Investigaciones Arqueológicas R. P. Gustavo Le Paige s. j., Universidad del Norte, San Pedro de Atacama, CHILE.
Museo Arqueológico local hacían predecir que el sector de Tulor sería promisorio para iniciar la búsqueda de antecedentes sobre esta etapa. Fue así como se elaboró un proyecto bajo estas consideraciones, el que fue aprobado por la Dirección de Investigaciones de la Universidad del Norte. Los trabajos, que se iniciaron en junio de 1982, llevaron al sorprendente resultado de que lo que se veía sobre la superficie de de Tulor 1 no eran los cimientos de tapias, como se creía hasta el momento, sino la parte superior de los muros de un complejo sitio estructurado, cubierto por el avance de las arenas del desierto. ${ }^{2}$

Las excavaciones acusaron, salvo leves variaciones, una misma estratigrafía básica en toda el área excavada. Es posible diferenciar dos horizontes de ocupaciones: uno en la superficie actual, y el otro, sobre los pisos de los recintos, separados ambos por una capa de arena prácticamente estéril, que ocupa entre 80 y $120 \mathrm{~cm}$ de espesor. El horizonte superior, con un grosor de $15-20 \mathrm{~cm}$, presenta una matriz suelta de arena con algo de arcilla; en ella está incorporado el material cultural que tapiza la superficie del sitio. Luego viene la acumulación de arena que, especialmente en las unidades exteriores, entregó algún material cultural; pero en los recintos cerrados, casi nada. Es común encontrar bloques y depositaciones de arcilla inmersos en esta acumulación, producto del derrumbe y derrubio de las paredes. Bajo la arena se encuentra el horizonte inferior de ocupaciones, con espesores que varían tanto entre los recintos, como en los distintos sectores de un mismo recinto $(10-30 \mathrm{~cm})$. En este horizonte están contenidas las evidencias de los ocupantes originales del poblado. El horizonte inferior muestra claramente dos estratos: uno de arcilla compacta y, bajo él, otro con predominio de

2 En diferentes aspectos de los trabajos se contó con la colaboración de M. Antonietta Costa (Instituto de Investigaciones Arqueológicas San Pedro de Atacama), Thomas Lynch (Universidad de Cornell) y Ann Peters (Universidad de Cornell). 
arena fina semicompacta; en este segundo estrato se pueden distinguir finas estrías de depositación eólica. El piso final está constituido por la superficie del sustrato natural de arcilla, que se ubica aproximadamente a $120 \mathrm{~cm}$ bajo el piso actual. La superficie del piso original presenta un delgado estrato compacto de arcilla mezclada con arena.

\section{Arquitectura}

El conjunto arquitectónico ocupa, en el sector que no ha sido cubierto totalmente por las arenas, una superficie de $3000 \mathrm{~m}^{2}$; aparentemente, la superficie total sería más extensa de acuerdo a vestigios que asoman sobre la superficie en el lado sureste. Se presenta como un conglomerado estructural, cuya base la dan 22 recintos circulares, en torno a los cuales se construyó un complejo sistema de murallas que confieren al conjunto un aspecto de laberinto (Figura 1). Los recintos circulares, pese a su circunferencia perfecta, presentan una distribución desordenada; esto junto con la irregularidad de los muros complementarios, hacen visualizar un patrón aglutinado de crecimiento celular. Queda en evidencia que lo primero que se construyó fueron los recintos circulares y, posteriormente, se fueron adosando muros, conformando nuevos recintos irregulares y pasillos de circulación.

El conjunto arquitectónico fue asentado directamente sobre el sustrato de arcilla, que hoy yace a $120 \mathrm{~cm}$ bajo la superficie actual. Para dar soporte a los muros se cavaron canaletas en este sustrato compacto y, en ellas, se asentó la primera fila de adobones que dan soporte a la construcción de cada recinto. Como material de albañilería se usó solo barro: bloques rectangulares dispuestos en filas superpuestas unidos con argamasa del mismo material. Los bloques de cada fila son bastante regulares en su altura, aunque cada fila tiene una altura diferente (Figura 2). Por ultimo, las superficies de los muros fueron estucadas también con una capa de barro.

Frente a la irregularidad de los recintos no circulares, llama la atención el módulo adosado a los recintos 5 y 6 por lo rectangular de sus ángulos, resaltando como una modalidad diferente al patrón general del conjunto. En este sector, que posiblemente sea un aditamento más tardío, Le Paige exhumó algunos enterratorios, que parecen relacionados con la ocupación de la superficie actual.
Por el borde oeste del conjunto corre un muro, que en el cuadrante suroeste mantiene un espesor de $1 \mathrm{~m}$, y que disminuye a la mitad en su recorrido norte. De su extremo sur se desprende otro muro más delgado. En la parte gruesa del muro principal se distinguen dos forados que posiblemente correspondan a puertas de acceso. La continuidad del muro no es clara en el resto del contorno, por lo cual su función es impredecible todavía.

Los recintos circulares se presentan como construcciones abovedadas, con paredes cóncavas hacia el interior, y con diámetros que van desde los 3 a los $8 \mathrm{~m}$ (Figura 3). Hasta el momento es difícil determinar las características de la parte superior de estas construcciones ya que se encuentran conservadas máximo hasta una altura de $1.90 \mathrm{~m}$. El barro caído sobre el piso de los recintos señala una mayor altura de los muros, pero no parece tan abundante como para sugerir una bóveda completa de barro, al menos en los recintos mayores. En el piso del Recinto 2 hay ocho orificios junto al muro, casi equidistantes, y con inclinaciones hacia el centro del círculo, dando ángulos que fluctúan entre $63^{\circ}$ y $80^{\circ}$. En el Recinto 3 hay cinco horadaciones con las mismas características; esto estaría poniendo en evidencia un sistema de postación, como estructura de soporte para la parte superior de estas construcciones. Los postes inclinados se complementan, al parecer, con un poste central en el Recinto 3, y con un juego de cinco postes verticales, en el Recinto 2 (Figura 4).

Otras horadaciones en los pisos de los recintos circulares parecen haber cumplido funciones como pozos de almacenaje. Estos pozos tienen diámetros que fluctúan entre 60 y $70 \mathrm{~cm}$ y profundidades que van de 50 a $60 \mathrm{~cm}$. Hay tres en el Recinto 3 y dos, en el Recinto 2. Materiales diversos fueron recuperados del interior de ellos, tales como fragmentos de cerámica, puntas líticas, restos animales, restos vegetales, etc.

En la Figura 5 se puede apreciar la distribución de vanos que comunican unos recintos con otros. En el sector excavado quedó a descubierto un total de 21 vanos, correspondiendo seis de ellos al Recinto 2 . De estos seis vanos, cinco se encuentran clausurados y sólo uno de ellos estuvo en funciones al fin de la ocupación. La clausura de vanos y apertura de nuevos parece que fue algo común en el sitio, seguramente obedeciendo a readecuaciones funcionales y de circulación. 


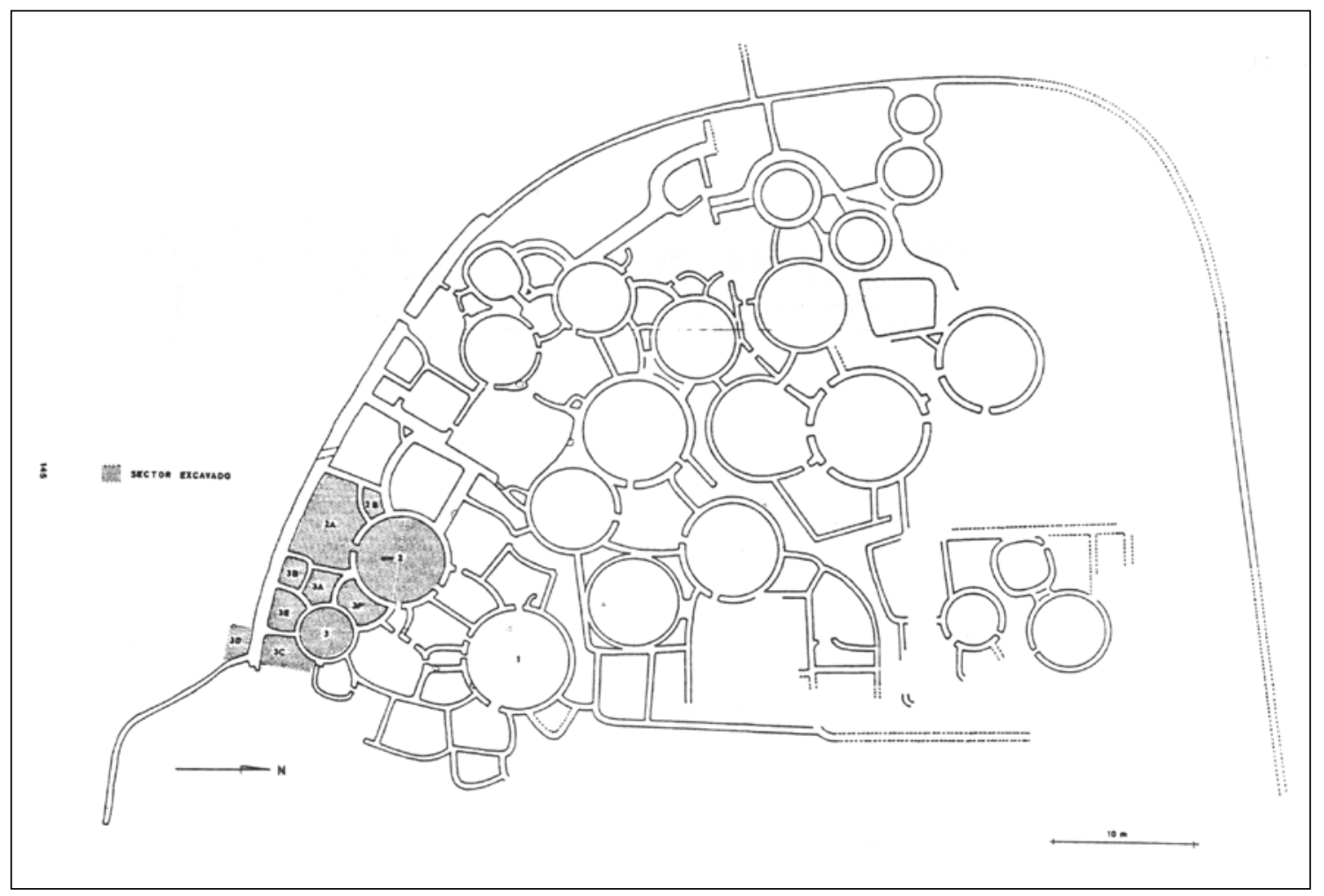

Figura 1. Tulor 1. Dibujo de Agustín Llagostera.

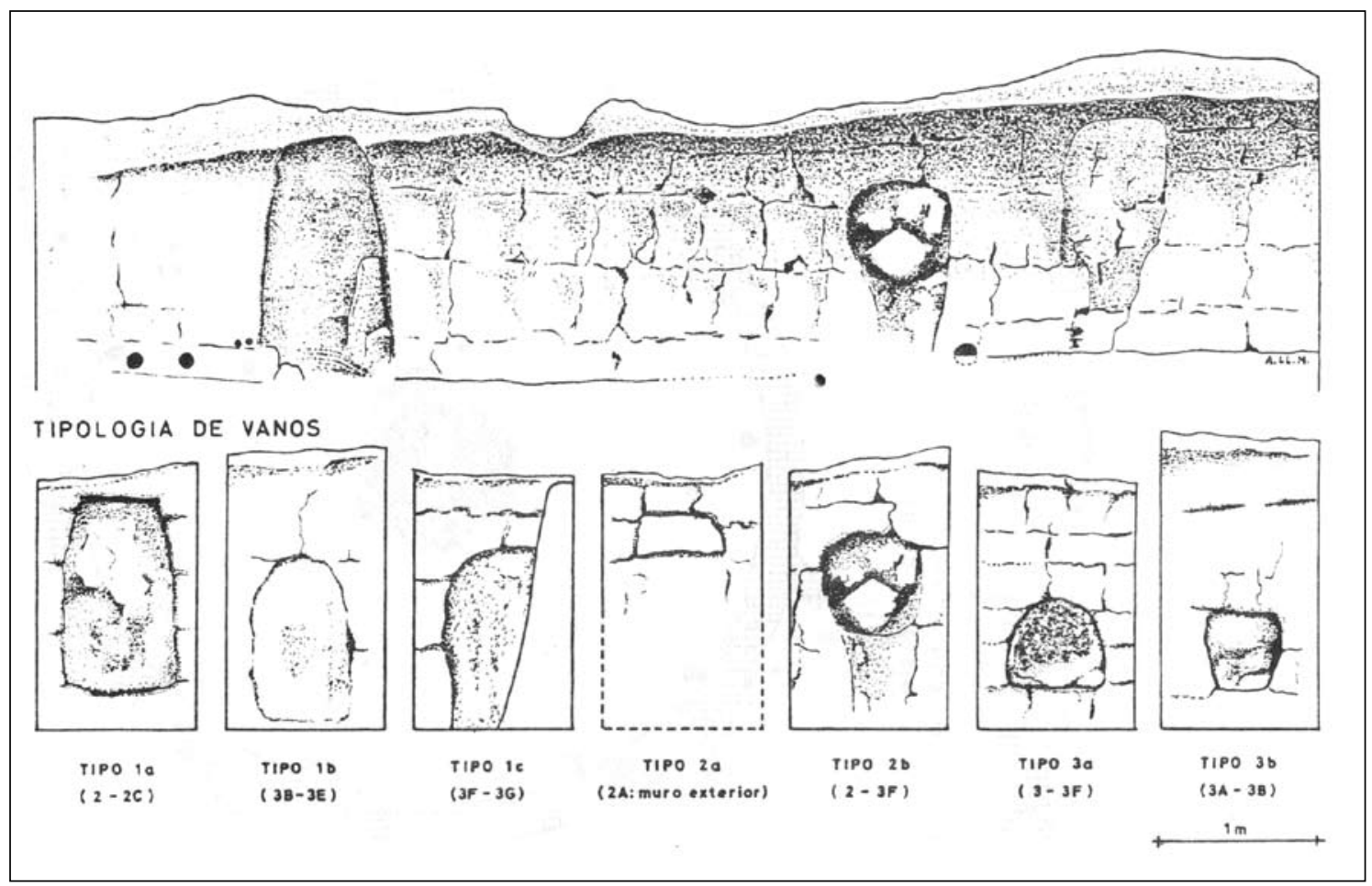

Figura 2. Segmento de la pared interior del Recinto 2 de Tulor 1. 
Los vanos no presentan un patrón uniforme. Dentro de su amorfismo, las formas más definidas tienden al trapecio (Figura 4). Los umbrales no tienen armazón, son recortados y rematados en el propio muro; solo un caso (2A-3A) parece haber tenido dintel de madera.

Según el tamaño y su ubicación en altura, en relación al piso, los 21 vanos pueden agruparse en tres tipos, cada uno de los cuales puede dividirse a su vez en subtipos según su forma (ver Figura 4). El tipo 1 corresponde a vanos grandes, con alto de abertura entre 84 y $118 \mathrm{~cm}$, y un ancho promedio de $65 \mathrm{~cm}$. Seis de éstos tienen forma trapezoidal (1a), cuatro ovoidales (1b), y dos se ubican en el rincón en que se adosan dos paredes perpendiculares, de tal manera que uno de los lados del marco está constituido por la pared que intersecta a la del vano (1c). El tipo 2 agrupa vanos pequeños, ubicados en la parte alta de los muros. Dos tienen forma trapezoidal o subrectangular (2a); uno de ellos, abierto en el muro circundante del poblado, al parecer fue un vano mayor que se tapió y se dejó abierta su parte superior $(24 \times 50 \mathrm{~cm})$; hay otro de mayores dimensiones $(63 \times 82 \mathrm{~cm})$ en el Recinto 2. Dos más tienen forma subcircular (2b), uno se sitúa a $60 \mathrm{~cm}$ del piso y el más pequeño, a $118 \mathrm{~cm}$ del mismo. Un tercer tipo (Tipo 3), está representado por vanos pequeños, ubicados en la parte inferior de los muros; hay dos de forma ojival (3a) y uno trapezoidal invertido (3b).

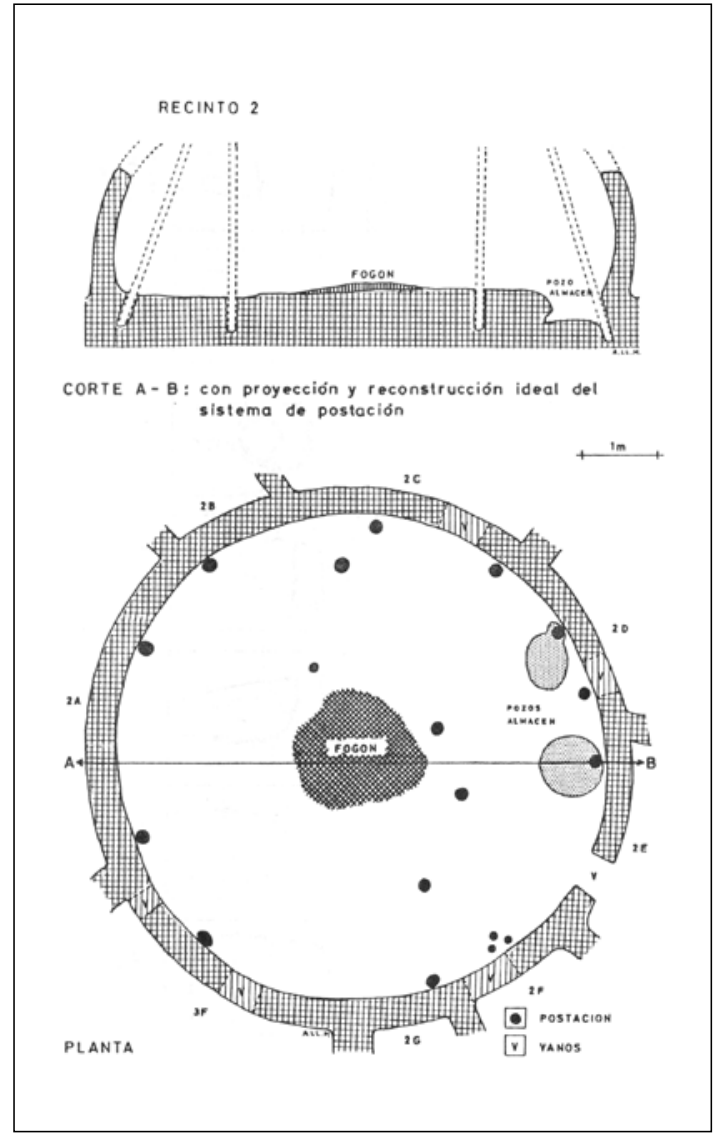

Figura 3. Recinto 2 de Tulor 1.

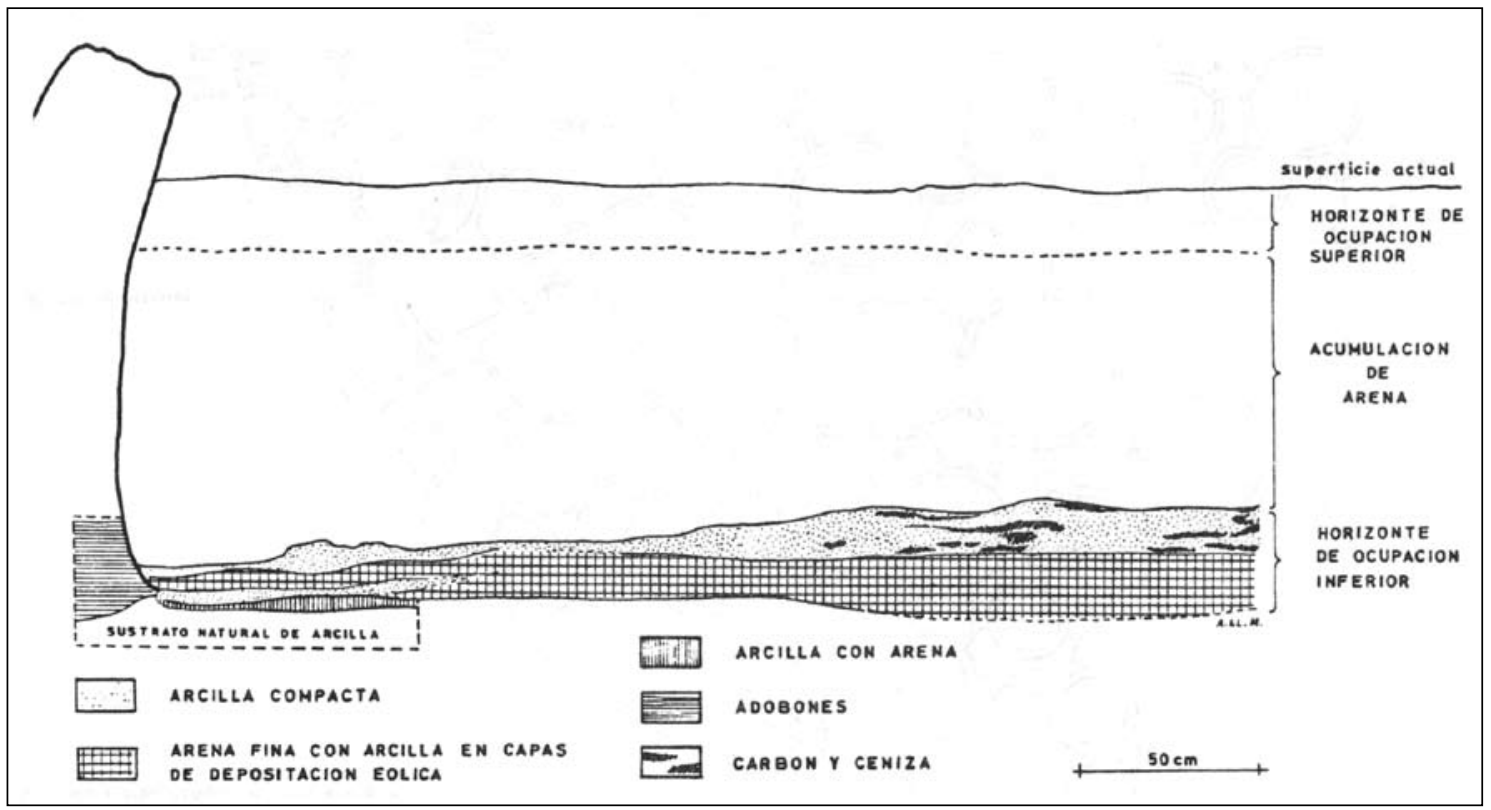

Figura 4. Estratigrafía del Recinto 2 de Tulor 1. 


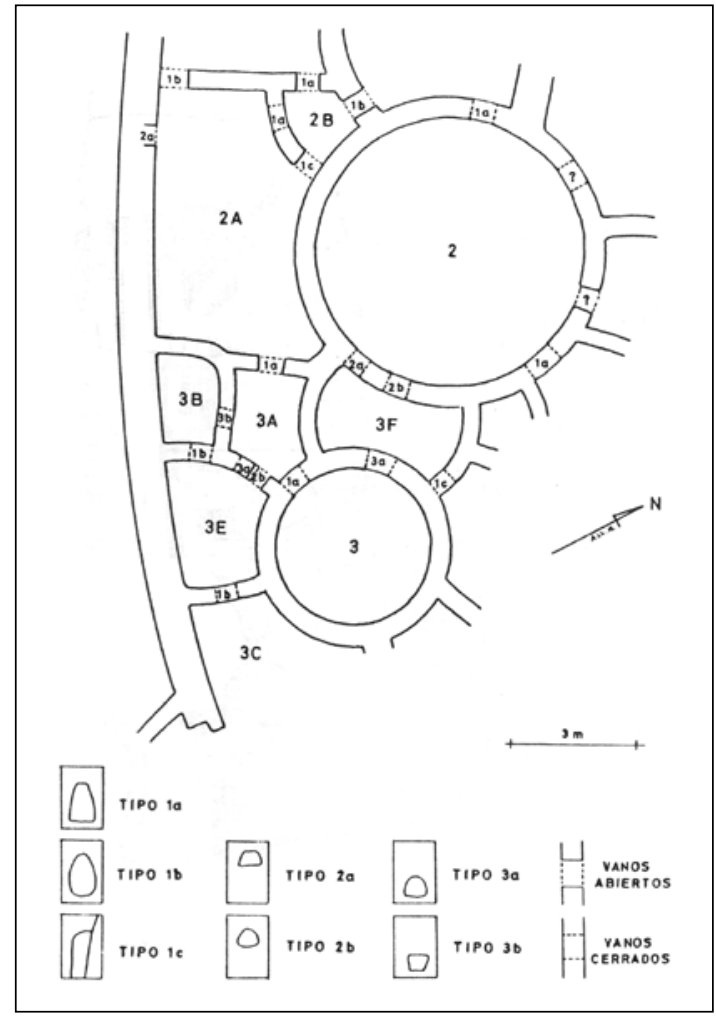

Figura 5. Tulor 1: Distribución de vanos en el sector excavado.

Los vanos del primer tipo evidentemente han servido de puertas para la circulación de la gente. Aquellos del Tipo 2, situados en la parte alta de las murallas, pueden haber cumplido funciones de ventanas, $\mathrm{y}$ los del Tipo 3 pueden haber sido accesos a recintos que en algún momento fueron utilizados como almacenes.

El patrón arquitectónico, en general, tiene tendencia a las formas abovedadas. Al observar el plano de planta puede apreciarse un predominio de paredes curvas. Todas estas paredes son cóncavas a favor de la curvatura; por ejemplo, en el caso del Recinto 3F, las dos paredes que unen los recintos 2 y 3 dan base a la conformación de una semibóveda.

\section{Cerámica $^{3}$}

La cerámica se encuentra distribuida en los dos horizontes de ocupaciones, con manifiestas diferencias entre ambos conjuntos.

\footnotetext{
3 Los análisis petrográficos fueron efectuados en el Departamento de Geociencias de la Universidad del Norte y los análisis por difracción de rayos X, en Minera Utah de Chile Inc.
}

El horizonte superior presenta predominio de un tipo de cerámica común, sin técnicas pigmentarias, con sus superficies brochadas y alisadas; generalmente, el alisado se ha realizado sobre el brochado. Su pasta es poco compacta y de porosidad mediana. Los principales clastos integrados en la pasta son: feldespatos, plagioclasas, fragmentos de tobas vitrocristalinas; biotitas en cristales y listoncillos, cuarzo en fragmentos irregulares, vidrios volcánicos, augita y hornblenda. Los minerales opacos están representados por óxido de hierro y titanio. El tamaño de granos varía entre $1 \mathrm{~mm}$ y 100 micrones. La matriz está compuesta por minerales de arcilla limonitizados, cocidos y en parte vitrificados; además de finísimos restos de biotita, clorita, anfíboles y sericita. Los espesores de los fragmentos van desde 5 hasta 10 $\mathrm{mm}$, y denotan formas ovoides con cuello ancho y asa vertical labio-adherida; algunas de estas vasijas tienden a piriformes por lo poco pronunciado del cuello. Esta cerámica, en sus formas y características, es similar a la cerámica utilitaria que aparece en los contextos de tumbas de los distintos cementerios de San Pedro de Atacama. Es la cerámica más abundante en Tulor 1 , con un promedio de $440 \mathrm{~g} / \mathrm{m}^{2}$ de superficie (en cuanto a masa de arcilla utilizada).

El otro tipo predominante, en la ultima ocupación del sitio, está representado por fragmentos de superficie gris, con estrías de bruñimiento. La pasta es compacta, de textura fina y baja porosidad; núcleo gris, y la superficie de aquellos fragmentos más claros tienden al castaño-rojizo por teñido con oxido de hierro; parte de esta oxidación ha sido conseguida también en la cocción. El análisis petrográfico señala presencia de abundantes clastos de cuarzo volcánico, plagioclasa zonada, hornblenda verde y marrón, tobas vitrocristalinas y contenidos menores de vidrios volcánicos, epidota, opacos (magnetita ilmenita) y biotita. El tamaño de grano varía entre $0.5 \mathrm{~mm}$ y 100 micrones. La matriz muestra abundantes restos de biotitas. Es discutible si este tipo es el mismo que ha sido definido como San Pedro de Atacama Negro Pulido (Tarragó 1976). Podría pensarse que el color gris ha resultado de la erosión de la superficie pulida, pero el análisis de un fragmento del típico negro pulido, también existente en el sitio, señala algunas diferencias: presencia de óxido de hierro en la superficie del primero y escasez de biotita en la matriz del segundo. De momento, estaríamos considerando todos ellos como integrantes de un mismo tipo, con variaciones secundarias en la técnica. Los espesores de los fragmentos fluctúan entre 4 y $5 \mathrm{~mm}$. Las formas corresponden a las 
descritas por Tarragó (1976) como vasos simples, no restringidos, troncocónicos invertidos (Forma III) y muy escasas vasijas simples restringidas, que se aproximarían a la Forma IX. Las otras formas descritas por Tarragó no se hacen presentes y mucho menos los clásicos botellones globulares. El peso de masa de arcilla de este tipo da un promedio de $147 \mathrm{~g} / \mathrm{m}^{2}$, correspondiendo una proporción de 1:3 en relación al tipo anterior.

Otros tipos no bien definidos aún aparecen en baja representatividad; entre ellos, uno que presenta la superficie exterior negra semipulimentada, mientras que la interior es algo más rojiza que el centro debido a oxidación; su estructura es compacta y la matriz presenta finísimos restos ferromagnesianos. Otro, de fragmentos gruesos, con superficies negras veteadas de gris, contiene una alta concentración de analcima, uno de los minerales de zeolita.

El horizonte de ocupaciones inferiores contiene menor cantidad de cerámica que el superior, pero más diversificada en sus tipos. Hay presencia de cerámica con superficie externa negra pulimentada y el resto castaño-rojizo; en ella predominan clastos de cuarzo volcánico, tobas vitrocristalinas y plagioclasas; las biotitas son abundantes en la matriz. Son fragmentos gruesos con decoración de líneas incisas (Figura 6a). Hay otros similares, pero de acabado más cuidadoso que parece estar relacionado con el complejo San Francisco de las Selvas Orientales (Figura 7a). Las cerámicas negras, en general, parecen ser variadas. Un tipo de fragmentos también gruesos, con sólo la cara exterior negra pulida, presenta pasta con abundantes fragmentos de lutitas negras algo pizarrosas, con sulfuros de hierro coloidales algo limonitizados, arcillas carbonatadas, calizas, margas y lutitas cuarzosas. Otro tipo con el núcleo gris muestra ambas superficies castaño-rojizas, pero en la externa se ha agregado un engobe negro; la pasta tiene fragmentos poiquilíticos de microclina, algo de feldespato de potasio y plagioclasas, monovita y trozos de rocas de cuarzo feldespático. Estos análisis hacen ver que las fuentes de obtención de las materias primas fueron distintas a las de superficie.

Es interesante la presencia de una cerámica marrón pulida con manchas negras, destacando un vaso (Figura 6b), vasija simple de boca no restringida, cilíndrica, comparable con la Forma I de la cerámica San Pedro Negro Pulido (Tarragó 1976), forma que también se hace presente en el Rojo Pulido de San Pedro de Atacama. En el mismo tipo de alfarería, pero de paredes más gruesas, aparece un cuello hiperboloide de borde evertido que correspondería a un cuerpo esferoidal. Algunos ejemplares de cerámica engobada, que van del rojo-ladrillo al marrón, incrementan la complejidad de los tipos. La cerámica común, macroscópicamente similar a la de la superficie del sitio, presenta en su pasta fragmentos de feldespato de potasio (ortoclasa), plagioclasa y cuarzo, fragmentos que podrían derivar de rocas riolíticas o graníticas. Como única alfarería pintada se encontraron tres fragmentos color crema con decoración en negro y bermellón, identificados con el estilo Vaquería del Noroeste Argentino (Figura 7b). ${ }^{4}$

En general, podemos decir que, en el horizonte de ocupación de los habitantes originales del poblado, se da una variedad de tipos ceramológicos que todavía es necesario definir con mayor exactitud.

\section{Restos animales $^{5}$}

La colección de restos faunísticos recuperados en las excavaciones del sitio corresponde mayoritariamente a restos de camélidos; sólo unos pocos fragmentos proceden de roedores pequeños (Ctenomys?). Los restos de animales están representados por material óseo, en condiciones extremadamente fragmentarias, y unos pocos coprolitos aún no identificados. Las características fisicoquímicas de la matriz del sitio han contribuido a la fragmentación de los huesos, favoreciendo el crecimiento de cristales de sal en ellos, y provocando la correspondiente tensión y ruptura de ellos. Dadas las condiciones del material, no es posible especificar a cuál o cuáles de las especies de camélidos corresponden estos vestigios.

A través de algunos fragmentos fue posible obtener alguna información sobre el patrón de mortalidad sufrida por los camélidos. Es así que se puede asegurar que los animales fueron usualmente sacrificados en su temprana vida de adultos, aunque algunos huesos sugieren la presencia de individuos neonatos o muy jóvenes.

El examen de la distribución de elementos óseos indica, en general, una escasez de las partes

4 Se contó con la colaboración de Myriam Tarragó en la identificación de algunas cerámicas.

5 Con la colaboración del Dr. Brian Hesse del Departamento de Antropología de la Universidad de Alabama en Birmingham. 


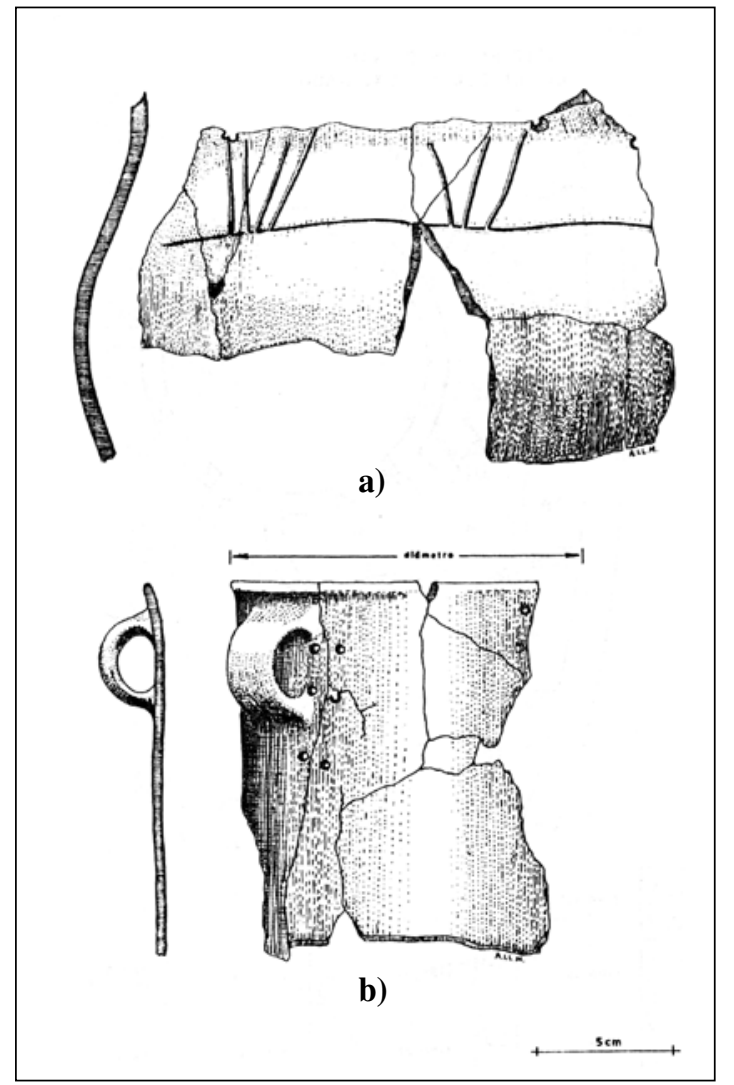

Figura 6. Tulor 1. Cerámica.

preferenciales del esqueleto que poseen carne. Los huesos largos están representados especialmente por fragmentos del cilindro central (diáfisis). Hay fragmentos vertebrales, pero no en la cantidad de fragmentos de centrum y de costillas proximales que debiera de haber si las partes carnosas de la espalda estuvieron presentes. La mayor concentración de restos óseos se encontró en las unidades 3C, 3D y 3F. Las dos primeras muestran las más claras evidencias de faenamiento y de partes carnosas, esto señalaría que el procesamiento de los animales se efectuaba fuera de los recintos, y sólo partes de ellos eran llevadas al interior. La ausencia de huesos portadores de carnes en los recintos cerrados confirma lo anterior, y los restos que allí se encuentran afirman la conducción de determinadas piezas del animal: el cráneo, por el consumo del cerebro, y los metapodios, para la médula, tendones y materia prima para herramientas y objetos.

Otros restos animales están representados por un escaso número de fragmentos de conchas de moluscos marinos; destacan almeja (Protothaca thaca), ostión

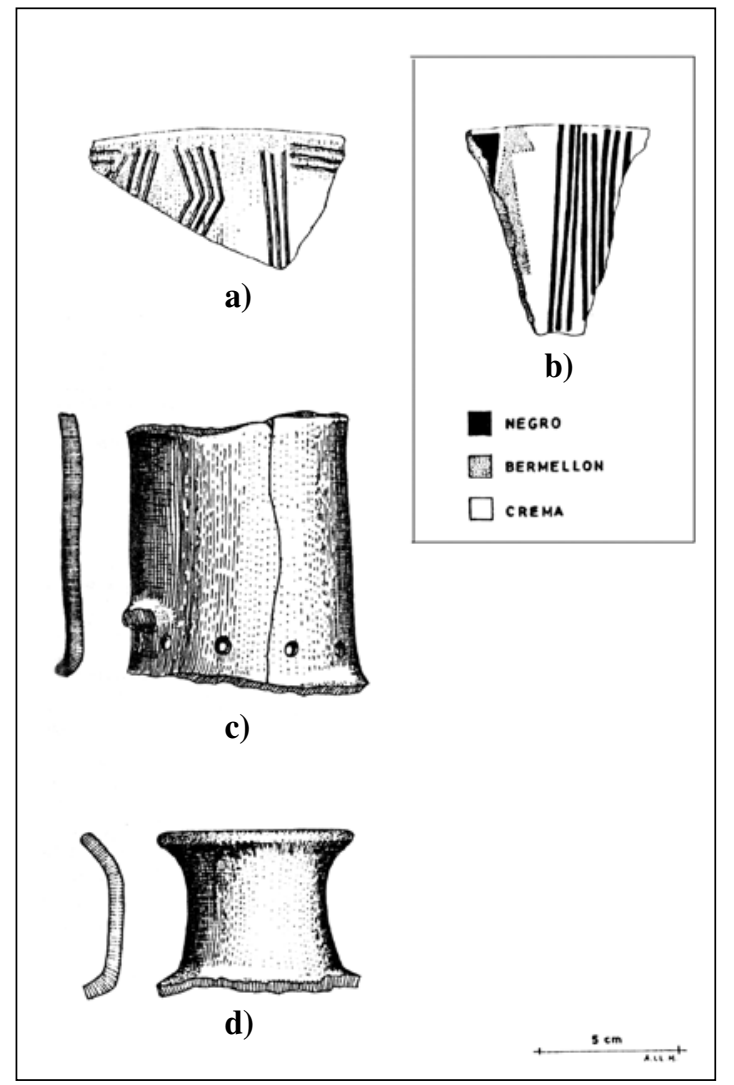

Figura 7. Tulor 1. Cerámica.

(Argopecten purpuratus), oliva (Oliva peruviana) y litorina (Littorina peruviana). Sin duda, estos elementos estaban relacionados con la ornamentación y la parafernalia mágico-religiosa.

\section{Restos vegetales}

La conservación de restos vegetales es prácticamente nula. Sólo se han conservado algunas evidencias carbonizadas, especialmente dentro de los pozos en el piso de los recintos circulares. Un minucioso examen del contenido de estos pozos permitió la identificación de una buena cantidad de algarrobo (Prosopis chilensis) y de maíz (Zea mays). Cabe destacar a este respecto el pozo 1 del Recinto 2 , el que por su alto contenido de estos productos quedó evidenciado como pozo-almacén, corroborando con ello la igual funcionalidad de otros pozos (p.e., pozos 1,2 y 11 del Recinto 3 y pozos 1 y 13 del Recinto 2).

En el barro, derrumbado de la parte superior de las construcciones, aparecen algunas improntas de 
vegetales de nervadura paralela. Un fragmento de cordel, confeccionado en fibra vegetal (de $10 \mathrm{~mm}$ de diámetro y dos cabos en torsión Z), fue encontrado en el fogón central del Recinto 2. Hasta el momento no ha sido posible determinar las especies que proporcionaron el ramaje que fue usado como combustible de los fogones, aunque en uno de los fogones del Recinto 2 se distinguieron ramas y vainas de algarrobo.

\section{Miscelánea}

En los estratos superficiales del sitio, a cambio de la abundancia de cerámica, otros materiales son escasos. Se hacen presentes algunos instrumentos líticos, cuentas de collar y fragmentos de mineral cuprífero.

Como elementos propios de la superficie del sitio, pueden considerarse los enterratorios excavados por Le Paige y tres exhumados por nosotros en el área de excavación, además de otros que sólo hemos detectado y ubicado. En el Recinto 3, en la depositación de arena, apareció un cuerpo extendido en posición decúbito lateral izquierdo, con el brazo derecho flectado bajo el cráneo y sin ajuar. Se trata de un individuo masculino adulto, que probablemente murió en el sitio antes de que el Recinto se rellenara completamente de arena. En el Recinto 3A, restos de un entierro de niño, y en el Recinto 3F, sólo la región pelviana de un cuerpo, acompañado de dos ceramios negros pulidos como ajuar. Las evidencias muestran que las otras partes de este último cuerpo se desintegraron por intemperismo, al perder parte de la arena que lo cubría por acción del viento.

La mayor diversidad de objetos se encuentra en la ocupación basal del sitio. Hay muchos objetos líticos confeccionados con materiales de origen volcánico, tales como puntas de proyectil, preferentemente pedunculadas y con aletillas, hechas en obsidiana con tamaños que van de 6 a $2.8 \mathrm{~cm}$. Perforadores de diferentes tamaños y formas (cabe destacar la presencia de 27 ejemplares en el Recinto 3); hachas y palas líticas; guijarros pulidores; instrumentos lascados, variados en formas y funciones, además de núcleos y lascas. Piedras talleres planas, morteros generalmente partidos, y manos de morteros.

Entre los objetos de hueso se distinguen un fragmento de espátula, cajas confeccionadas en diáfisis (una de ellas con aparente decoración pirograbada), un fragmento plano de hueso con triple hilera de puntos incisos, y una cantidad de fragmentos de objetos no definibles.

Para cerrar la miscelánea, debemos agregar cuentas de collar, polvos rojos y amarillos, piedras de mineral de cobre y un pequeño cincel de cobre.

\section{Cronología}

Dos muestras de carbón vegetal fueron procesadas en el laboratorio de la Universidad de Pensilvania. Una tomada en el Recinto 3 (P-3350) y la otra en la Unidad 3C (P-3351). Ambas corresponden al horizonte de ocupación inferior; vale decir, están asociadas con los ocupantes originales de la aldea.

\begin{tabular}{|lll|}
\hline $\begin{array}{l}\text { Muestra P-3350: } \\
\text { (5568 vida media) }\end{array}$ & $2540 \pm 60 \mathrm{AP}$ & $590 \pm 60 \mathrm{AC}$ \\
(5730 vida media) & $2620 \pm 60 \mathrm{AP}$ & $670 \pm 60 \mathrm{AC}$ \\
CRD-10-: 800 a $600 \mathrm{AC}$ & & \\
& & \\
Muestra P-3351: & & \\
(5568 vida media) & $1800 \pm 60 \mathrm{AP}$ & $150 \pm 60 \mathrm{DC}$ \\
(5730 vida media) & $1850 \pm 60 \mathrm{AP}$ & $100 \pm 60 \mathrm{DC}$ \\
CRD-10-: 200 a 245 DC & & \\
\hline
\end{tabular}

El comentario hecho por el mencionado laboratorio señala que la fecha P-3351 es la más confiable de las dos, ya que la muestra P-3350 no contenía material suficiente para el pretratamiento con hidróxido de sodio y remover los contaminantes húmicos.

\section{Discusión}

Antecedentes de una arquitectura semejante a la de Tulor 1 se encuentran en el altiplano boliviano, en el norte chileno y en el Noroeste Argentino.

En el altiplano se asocian con la cultura Wankarani, la que se distribuye al norte del lago Poopó (Ponce 1970). De todas las localidades adscritas a esta cultura destacan Wankarani, Kella Kollu, Pakasa, Kelkaña y Uspa Uspa, todas ellas extensas y de densa agrupación. Las dos primeras presentan, al igual que Tulor, una muralla circundante. Las excavaciones en Wankarani dejaron a descubierto, además, diámetros de recintos similares a los de Tulor, hoyos para postes, fogones dentro de los recintos y adobes como elementos de construcción. 
En el norte chileno, Caserones (Núñez 1982), a pesar del patrón de estructuras rectangulares, se asemeja a Tulor en el sistema de postación, en los depósitos socavados, en las pequeñas piezas esquinadas y en el muro circundante. Guatacondo (Mostny y Niemeyer 1963; Mostny 1965, 1970; Meighan 1980) manifiesta una notable similitud con nuestro sitio. Presenta recintos circulares entre 2.2 y $5.1 \mathrm{~m}$ de diámetro, construidos con grandes adobones en su parte basal y con adobes rectangulares o aproximadamente esféricos en su parte superior. Los pozos de almacenaje más comunes en Guatacondo (Meighan 1980) son los mismos que en Tulor, hasta casi con los mismos contenidos. Se diferencia Guatacondo de este último en la existencia de una plaza central, en la ausencia de un muro circundante y en que los recintos circulares son todos yuxtapuestos, faltando el entramado de laberintos entre los círculos.

En el Noroeste Argentino tenemos Potrero Grande y Las Cuevas en la quebrada del Toro; Tafí, al oriente del Aconquija; dos sitios en Ingenio del Arenal, Catamarca; Tebenquiche y Laguna Blanca en la Puna meridional; Campo Colorado en el valle Calchaquí, delimitado este último por un muro circundante.

Dentro de un patrón general, hay características que definirían el patrón del Noroeste Argentino como propio de esa región. La coincidencia de plantas circulares es indiscutible, y los espacios circulares o rectangulares a los que se adosan los recintos, de alguna manera recuerdan la plaza de Guatacondo. Pero ninguno de los sitios descritos en la literatura argentina presenta la densidad de los precedentes, son conjuntos que rara vez sobrepasan la media docena de estructuras. El material de construcción siempre fue la piedra. Por otro lado, estos núcleos de población parecen estar dispersos entre andenes y terrazas y no en la desembocadura de quebradas, excepto Ingenio del Arenal y Laguna Blanca, cuyos sitios se encuentran en las partes bajas de típicos conoides en los flancos de las desembocaduras de las respectivas quebradas. En estos casos se encuentran incluidos en las proximidades de "canchones" de cultivos.

Wankarani tiene una fecha de $1210 \pm 110$ AC para la primera ocupación, y Ponce (1970) estima que esta cultura continuó hasta las primeras centurias de la era cristiana. Caserones, según Núñez (1982), acusaría los momentos iniciales del poblado entre $400 \mathrm{AC}$ y el año 0, desarrollando su clímax habitacional entre 0 y 600 DC. Para Guatacondo, Mostny (1965) da

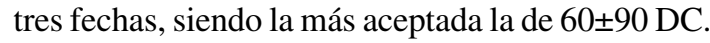
Los conjuntos del Noroeste Argentino se encuentran asociados preferentemente a elementos Tafí I, Ciénaga, Condorhuasi y Candelaria, lo que daría un espectro diacrónico entre 300 AC y 600 DC.

Las fechas de Tulor son perfectamente coherentes con este panorama general, panorama que señalaría al Altiplano meridional como el lugar de origen del patrón arquitectónico que nos ocupa. La fecha más temprana de Tulor (P-3350) podría ser aceptada a pesar de la supuesta contaminación húmica; sin embargo, la dejaremos de lado hasta que sea confrontada con otras muestras. Otra fecha $\mathrm{C}^{14}$ conseguida por uno de los autores estaría indicando 345 años AC como fecha temprana para este sitio (Barón 1983). La fecha P-3351 de 100 y 150 DC, que con el ajuste CRD-10- daría 200 a 245 DC, sin duda es válida para el momento de pleno funcionamiento de la aldea, ya que corresponde al interior de uno de los recintos.

La cerámica en Tulor 1 refleja claramente dos ocupaciones con características propias. La primera de ellas, de los ocupantes de los recintos, manifiesta una diversidad de tipos cerámicos, algunos de ellos evidentemente foráneos. La segunda, sobre la superficie actual, muestra mayor cantidad de cerámica, pero restringida prácticamente a dos tipos básicos.

Entre la cerámica de los ocupantes de los recintos, destaca el tipo Las Cuevas Tricolor (Cigliano et al. 1972) o Vaquería (Heredia et al. 1974), cerámica que en Argentina se le asignan fechas que van desde 200 AC hasta 400 DC. De todas las variantes de este tipo cerámico, la más parecida a la de Tulor es la de Guachipas (Salta). Heredia y colaboradores (1974) sostienen la hipótesis de que esta cerámica habría jugado el papel de "tres d'unión" entre las culturas del este, tales como San Francisco y en menor grado Candelaria, con las manifestaciones tempranas de la Subárea Valliserrana, como las de Condorhuasi y de la Puna, tanto en la región de San Pedro de Atacama como en el ámbito de la cultura Tebenquiche.

Otra cerámica foránea en poder de los aldeanos de Tulor corresponde al patrón inciso geométrico de las Selvas Occidentales (Dougherty 1974). Esta cerámica, que logra una amplia distribución desde Tarija y Lípez hasta Laguna Blanca, se ubicaría cronológicamente en los últimos siglos de la era precristiana y primeros de la cristiana. 
Las tradiciones monocromas propias de la meseta puneña y que tempranamente se manifiestan en la vertiente occidental (Turi Norte, Chiu Chiu 200), también están presentes en nuestro sitio. Formas de vasos subcilíndricos de base biplana y un asa cinta de inserción vertical, característicos de Tebenquiche, se insinúan en formas como en la Figura 6 b.

La primera ocupación de Tulor 1, de patrón arquitectónico aparentemente foráneo asociado a cerámica foránea y de tipos diversos, hace pensar en aportes que llegaron desde distintas regiones y lugares, consolidando un verdadero centro formativo. Los indicadores analizados hasta aquí nos muestran que lo que estaba sucediendo en el ámbito puneño en los últimos siglos AC está plenamente representado en Tulor. Este sector de San Pedro de Atacama se hallaba integrado a un universo muy amplio, abarcando desde las tierras bajas orientales hasta la costa del Pacífico, convirtiéndose en un foco de la actualidad social y cultural de ese espacio andino $\mathrm{y}$ de ese momento.

La segunda ocupación, con su cerámica estandarizada y escasez de alfarería foránea, refleja una población en desarrollo de patrones locales propios. Mientras las primeras evidencias correspondían a una ocupación primaria del poblado como tal, las últimas denotan una ocupación secundaria, sólo como cementerio por gente que vivía en lugares próximos.

Hay características comunes en relación a los lugares elegidos para los asentamientos aglutinados que contornean la Puna y que son de nuestro interés. Al parecer, los cursos finales de los ríos, donde la corriente pierde su ímpetu para formar remansos y terrenos anegados, fueron parte importante en los hábitat preferidos para fundar dichos poblados. Núñez (1974) sostiene que las ocupaciones portadoras de una agricultura temprana pudieron aprovechar las temporadas de agua y avenidas y los cursos permanentes superficiales y aun vertientes en los tramos inferiores de las quebradas de Tarapacá y Guatacondo. Meighan (1980), por su parte, afirma que en el primer milenio después de Cristo la mayoría de las quebradas tenían pueblos cerca del punto donde la quebrada desagua en la planicie interior (Pampa del Tamarugal), o sea, en la base de los piedemontes andinos. Fue por este tiempo que los sitios de Guatacondo y de Caserones pudieron ser soportados en parte por la agricultura incipiente de esas localidades. Con el paso del tiempo, y el gradual desecamiento de los canales de drenaje, no fue posible mantener asentamientos permanentes cerca de las bocas de esos canales, debiendo ser reubicados hacia elevaciones mayores donde el agua superficial podría ser todavía encontrada.

Esta parece ser la situación en San Pedro de Atacama. Los procesos agropecuarios comenzaron a consolidarse en el curso final del río San Pedro, justamente en el sector de Tulor. Allí las aguas, antes de desaparecer en el subsuelo, se apozaban e impregnaban la tierra de humedad y de nutrientes, formando un sustrato apto para la germinación de los productos hortícolas iniciales. También favorecían la proliferación de vegas, las que podían integrarse a circuitos de pastoreo de camélidos, especialmente como estaciones de invierno. Se conjugaba entonces un hábitat especial, donde el pastoreo y la horticultura podían coexistir consolidando una economía mixta e incorporando, además, los productos forestales del oasis (algarrobo y chañar).

En una primera fase pudo darse un sistema de asentamiento disperso, conformado por los diversos sitios que existen en el distrito de Tulor. Serracino, en Tulor 4, postula una primera de tres ocupaciones con material lítico hecho sobre vidrio volcánico, sin asociación con cerámica. "Esto hace suponer que el lugar tuvo una ocupación del Mesolítico antes de la cerámica" (Serracino 1976: 26). Hipotéticamente, podemos suponer que, más tarde, uno de estos asentamientos (Tulor 1) logró la consolidación aldeana a través de un crecimiento celular más intenso que el resto. Esto incentivado, además, por la necesidad de un núcleo centralizador que organizara las relaciones interregionales que se hacían cada vez más complejas.

La población inicial ocupó el sector de Tulor cuando las aguas del río San Pedro alcanzaban esos lugares. El posterior avance de las arenas y el retroceso del agua deben haber sido las principales causales del abandono del sitio. 


\section{REFERENCIAS CITADAS}

BARON, A. M., 1983. Tulor: 2400 años bajo tierra. Revista El Domingo de El Mercurio (6 de noviembre de 1983).

CIGLIANO, M., R. RAFFINO y H. CALANDRA, 1972. Nuevos aportes para el conocimiento de las entidades alfareras más tempranas del Noroeste Argentino. Relaciones de la Sociedad Argentina de Antropología VI: 225-236.

DOUGHERTY, B., 1974. Informe preliminar sobre un nuevo yacimiento arqueológico en Palpalá, Provincia de Jujuy. Su ubicación dentro del Complejo San Francisco. Relaciones de la Sociedad Argentina de Antropología VIII.

HEREDIA, O., J.A. PEREZ y A. R. GONZALEZ, 1974. Antigüedad de la cerámica policroma en el Noroeste Argentino. Revista del Instituto de Antropología V: 133-151.

LE PAIGE, G., 1957-1958. Antiguas culturas atacameñas en la cordillera chilena. Anales de la Universidad Católica de Valparaíso 4-5.

1964. El Precerámico en la cordillera atacameña y los cementerios del Período Agroalfarero de San Pedro de Atacama. Anales de la Universidad del Norte 3.

1973. El valor arqueológico del Museo de San Pedro de Atacama. Estudios Atacameños 1: 7-20.

1974. Informes de trabajo (Tulor y Coyo). Estudios Atacameños 2: 101-103.

1976. Apéndice sobre Tulor 4. Estudios Atacameños 4: 33-34.
MEIGHAN, C., 1980. Archaeology of Guatacondo, Chile. En Prehistoric trails of Atacama: Archaeology of Northern Chile. Monumenta Archaeologica 7, C. Meighan y D. True (Eds.), Universidad de California, Los Angeles.

MOSTNY, G., 1965. Fechas radiocarbónicas de la quebrada de Guatacondo. Noticiario Mensual del Museo Nacional de Historia Natural 105.

1970. La subárea arqueológica de Guatacondo. Boletín del Museo Nacional de Historia Natural XXIX (16): 271-287.

MOSTNY, G. y H. NIEMEYER, 1963. Informe sobre investigaciones arqueológicas en la quebrada de Guatacondo. Noticiario Mensual del Museo Nacional de Historia Natural 86.

NUÑEZ, L., 1974. La agricultura prehistórica en los Andes Meridionales. Editorial Orbe, Santiago.

_ 1982. Temprana emergencia de sedentarismo en el desierto chileno: Proyecto Caserones. Chungara 9.

PONCE, C., 1970. Las culturas Wankarani y Chiripa y su relación con Tiwanaku. Publicación de la Academia Nacional de Ciencias de Bolivia 25.

SERRACINO, G., 1976. Tulor 4: Cuatro pozos de sondeo. Estudios Atacameños 4: 24-31.

TARRAGO, M., 1976. Alfarería típica de San Pedro de Atacama (norte de Chile). Estudios Atacameños 4: 37-73. 